\title{
A survey of attitudes of patients in a department of genitourinary medicine
}

\author{
M. J. BALSDON, B. CHARLTON, M. CURRAN, AND H. S. K. SINGHA \\ From the Departments of Genitourinary Medicine and Community Medicine, Southampton University \\ Hospitals, Southampton
}

SUMMARY A questionnaire concerning clinic organisation was completed by 415 patients attending a department of genitourinary medicine. Most $(62.9 \%)$ patients preferred to be identified by number rather than by name, and about half $(52.7 \%)$ did not like mixed waiting rooms. An appointment system as well as having an open clinic was liked by twice as many (44.9\%) as those patients $(23.6 \%)$ against such a system. More information about sexually transmitted diseases in the form of leaflets, etc. at the clinic was requested by most $(79.1 \%)$ patients and a similar number $(82.0 \%)$ felt the department itself should be more widely advertised.

\section{Introduction}

The Venereal Disease Service in Great Britain was established sixty years ago. Despite radical changes in social conditions and in sexual behaviour and attitudes since then methods of organisation and practice at clinics have changed little in many departments. It has been suggested that the modern clinic dealing with sexually transmitted diseases should be organised in a manner similar to other medical clinics (Catterall, 1973). A document on the planning and design of larger departments has been issued by the Department of Health and Social Security (1974), but no information has been published on the attitudes of the patients to the design and organisation of clinics of genitourinary medicine.

The present department of genitourinary medicine at Southampton is situated near a main hospitalthe Royal South Hants. Patients are called by number, there is no appointment system, and there are separate waiting areas for men and women. A small amount of reading matter on sexually transmitted diseases, mainly pamphlets, is available in the waiting areas.

It was decided to assess the patients' attitudes towards these aspects of the clinic organisation and routine to help in making decisions about a new department planned as part of the new Royal South Hants Hospital.

Address for reprints: Dr M. J. Balsdon, Royal South Hants Hospital, Department of Genitourinary Medicine, Bullar Street, Southampton SO2 ONH

Received for publication 28 November 1977

\section{Materials and methods}

A questionnaire was drawn up and tested in a pilot survey. It was handed out by two medical students (BC and MC) who also collected the completed forms. This study formed part of the students' fourth year research project (Normand and Cantrell, 1976). Patients filled in the questionnaire while in the waiting room before seeing the doctor. Patients replied to the questions by ticking the appropriate boxes. One question had a space so that the patient could suggest places in which the clinic could be advertised, and there was also a space for 'other comments'. All clinic sessions were covered during the three-week study period.

\section{Results}

Four hundred and fifteen questionnaires were completed by patients ( 262 by men and 153 by women). Seventy-one per cent of the patients were under 30 years of age. The replies to the first four questions are summarised in Table 1 . Replies from men and women, and old and new patients, did not differ significantly so these have been amalgamated. More reading matter on sexually transmitted diseases at the clinic was requested by $79 \cdot 1 \%$ of the patients. A similar number $(82.0 \%)$ felt that the clinic should be advertised more. Sites mentioned by patients for advertising the clinic are shown in Table 2. 
Table 1 Replies to questionnaire

\begin{tabular}{llll}
\hline & \multicolumn{3}{l}{ Answer \% } \\
\cline { 2 - 4 } Question & For & Don't mind & Against \\
\hline $\begin{array}{l}\text { Do you like the present system } \\
\text { of being called by number? }\end{array}$ & 62.9 & 33.2 & 3.9 \\
$\begin{array}{l}\text { Would you prefer to be called } \\
\text { by name? }\end{array}$ & $12 \cdot 7$ & 34.4 & 52.8 \\
$\begin{array}{l}\text { Would you like an appointment } \\
\text { system at the clinic as well as } \\
\text { the present arrangements? }\end{array}$ & 44.9 & 31.4 & 23.6 \\
$\begin{array}{l}\text { Would you like husbands and } \\
\text { wives or boyfriends and } \\
\text { girlfriends sitting together in } \\
\text { the waiting room? }\end{array}$ & 22.8 & 24.4 & 52.7 \\
\hline
\end{tabular}

Table 2 Sites mentioned for advertising

\begin{tabular}{lcc}
\hline Sites & Males & Females \\
\hline Local newspapers and magazines & $28 \cdot 8$ & $23 \cdot 6$ \\
Public places* & $22 \cdot 3$ & $23 \cdot 0$ \\
Bars, clubs, and cinemas & $10 \cdot 2$ & $4 \cdot 4$ \\
Television and radio & $11 \cdot 3$ & $3 \cdot 7$ \\
Public lavatories & $8 \cdot 0$ & $6 \cdot 2$ \\
Colleges, schools, etc. & $6 \cdot 6$ & $9 \cdot 9$ \\
Doctors' surgeries, clinics, waiting & $5 \cdot 5$ & $16 \cdot 8$ \\
$\quad$ rooms & $7 \cdot 3$ & $12 \cdot 4$ \\
Others & $100 \cdot 0 \%(274)$ & $100 \cdot 0 \%(161)$ \\
Total (no. of times mentioned) & & \\
\hline
\end{tabular}

*Post offices, railway stations, etc.

\section{Discussion}

The fact that most patients in Southampton preferred to be identified by a number at the clinic was an interesting finding in view of the dissatisfaction expressed by some patients before the survey. The open nature of the waiting areas (they are really main corridors in continuous use by staff and patients) and the lack of adequate soundproofing in the Portakabin structure may be factors. Perhaps there should be more emphasis on confidentiality rather than anonymity. The percentage of patients who preferred the present system of numbers compared with the use of names for identification was approximately equal, confirming the strength of this finding.

Many patients would welcome an appointment system in addition to the present 'open' clinic arrangements. An appointment system for patients with difficult or protracted problems would ensure 'same doctor' management which was a point made by several patients in the questionnaire. A suitably organised appointment clinic would also ensure that medical students would see a constant flow of patients rather than erratic patient attendance as at the present open clinic.

Waiting rooms for men and women together were disliked. Although Southampton is a large city some patients stated that they might feel embarrassed, particularly if their contacts attended at the same time. This finding may again be related to the physical nature of the waiting areas. It is interesting to note that the smallest clinics in the specialty often have mixed waiting rooms and complaints from patients seem to be few. Perhaps the best solution would be to have a 'family room' for partners as well as 'singles' waiting rooms. Some clinics already have this arrangement.

Reading material on sexually transmitted disease is commonly requested by a patient. This request may be related to unwillingness to ask questions owing to embarrassment or because there is no time for adequate explanation in a busy clinic. Since the survey there has been a comprehensive stock of pamphlets in the waiting area and this has been much appreciated by patients.

There was general agreement that the clinic should be advertised more widely. The sites mentioned by patients for advertising may to some extent reflect individual life styles, but a quarter of all patients who mentioned sites quoted local newspapers and magazines. The female patients mentioned surgeries, clinics, and waiting rooms often enough to make these also worthy of consideration. In view of the interest shown in advertising in local newspapers we are considering having a suitably worded advertisement.

It was hoped that the replies to this questionnaire would give some ind ation of the patients' feelings on aspects of clinic organisation and this has been achieved.

We thank the staff and patients of the department for their help and co-operation and Professor W. E. Waters and Dr D. J. B. Barker of the Department of Community Medicine, Southampton University, for their advice.

\footnotetext{
References

Catterall, R. D. (1973). Changing patterns in the organization of the venereal disease service in Great Britain. British Journal of Venereal Diseases, 49, 126-129.

Department of Health and Social Security (1974). Special Treatment Clinic: A Design Guide. HMSO: London.

Normand, I. C. S., and Cantrell, E. G. (1976). Southampton: the first years. VI. The fourth year: study in depth. British Medical Journal, 2, 162-163.
} 